\title{
Sistema prisional brasileiro: desafios de um estado democrático de direito
}

O presente estudo visa a defesa da dignidade da pessoa humana diante da atual realidade dos presídios brasileiros, que apresenta problemas estruturais graves, acarretando não somete na violação de garantias fundamentais básicas do preso, como da sociedade como um todo, pois essas falhas estruturais do sistema acabam por potencializar a violência. Assim exposto surge o questionamento acerca da possibilidade de cumprimento das garantias fundamentais inerentes ao estado democrático de direito. Interessante se faz o desenvolvimento de um apanhado histórico sobre as fases de desenvolvimento da pena, descrevendo-as desde o período da Vingança Privada até o período da Nova Defesa Social, sendo necessário para mensurar o quanto evoluímos e o quanto estamos temporalmente atrasados. Diante do problema posto e das diversas violações de direitos, o Supremo Tribunal Federal acabou reconhecendo um Estado de Coisas Inconstitucional, que através de uma relação dialógica entre os poderes estatais, visa adaptar o sistema prisional brasileiro aos princípios inerentes ao Estado Democrático de Direito, principalmente no que tange a dignidade da pessoa humana, onde surge um interessante debate sobre o ativismo judicial e a real necessidade de garantir os princípios positivados na Constituição Federal. Os dados e os debates apresentados no presente trabalho deixam transparecer a gravidade da situação prisional brasileira e cria uma reflexão a respeito das possibilidades a serem adotadas para minimizar os efeitos das falhas estruturais presentes no sistema, principalmente no que tange a ineficácia de políticas públicas ou até mesmo a falta de vontade política para resolução desse grave problema social.

Palavras-chave: Sistema Prisional; Estado Democrático de Direito; Violações de Garantias Fundamentais.

\section{Brazilian prison system: challenges for a democratic rule of law}

The present study aims to defend the dignity of the human person before of the current reality of Brazilian prisons, which presents serious structural problems, causing not only the violation of basic underlying guarantees of the prisoner, but also of society as a whole, as these structural failures of the system end up potentiating violence. Thus exposed, the question arises about the possibility of fulfilling the fundamental guarantees inherent in the democratic rule of law. It is interesting to develop a historical overview of the stages of the development of the sentence, describing them from the period of Private Revenge to the period of the New Social Defense, being necessary to measure how far we have evolved and how long we have been behind schedule. Faced with the problem posed and the various violations of rights, the Supreme Federal Court ended up recognizing an Unconstitutional State of Things, which through a dialogical relationship between state powers, aims to adapt the Brazilian prison system to the principles inherent to the Democratic State of Law, mainly with regard to the dignity of the human person, where an interesting debate arises about judicial activism and the real need to guarantee the principles established in the Federal Constitution The data and debates presented in the present work reveal the seriousness of the Brazilian prison situation and create a reflection on the possibilities to be adopted to minimize the effects of structural failures present in the system, especially with regard to the ineffectiveness of public policies or even even the lack of political will to solve this serious social problem.

Keywords: Prison System; Democratic state; Violations of Underlying Warranties.

Topic: Direito Penal e Processo Penal

Reviewed anonymously in the process of blind peer
Received: $15 / 01 / 2020$

Approved: 29/04/2020
Rafael Rocha Silva (iD

Universidade Tiradentes, Brasil

http://lattes.cnpq.br/3956542711437931

https://orcid.org/0000-0002-1283-3283

rafael_rocha3112@hotmail.com
Referencing this:

SILVA, R. R.. Sistema prisional brasileiro: desafios de um estado democrático de direito. Justitia Liber, v.2, n.1, p.1-15, 2020. DOI: http://doi.org/10.6008/CBPC2674-6387.2020.001.0001 


\section{INTRODUÇÃO}

O Sistema Prisional Brasileiro é extremamente complexo, por vários motivos esse tema vem se tornando cada vez mais relevante, e o que mais chama a atenção é a violação massiva de direitos humanos sofridas pelos usuários do citado sistema, e como se não fosse suficiente, essas violações contam com o apoio de boa parte da população, a vibração popular com os maus tratos é uma forma de vingança, potencializando o que seria um 'direito penal do inimigo'1 ${ }^{1}$ O que não fica transparente é que a violação de direitos não afeta apenas o preso, mas a população de forma geral, ao contrário do que se pensa, a decadência do sistema prisional só faz aumentar a violência.

Nesse sentido, faz-se mister indagar: diante da atual realidade do sistema prisional brasileiro, é possível garantir o fiel cumprimento das garantias inerentes ao Estado Democrático de Direito?. O presente estudo tem por objetivo discorrer e discutir acerca das diversas violações de Direitos Fundamentais previstos no ordenamento pátrio, ocorridas no âmbito do sistema prisional brasileiro e apresentar soluções possíveis e eficientes que visem legitimar o Estado Democrático de Direito no âmbito do Sistema Prisional Brasileiro.

Interessante se faz expor dados fidedignos inerentes aos presídios brasileiros, possibilitando uma visão abrangente dos problemas inerentes ao sistema e ampliando as possiblidades de soluções a serem debatidas, além de analisar os diversos setores da sociedade que acabam por influenciar a decadência do Sistema Prisional, desenvolvendo uma percepção crítica acerca da amplitude de possibilidades de correção de condutas através de uma política criminal efetiva, que busque garantir a observância dos princípios explícitos e implícitos presentes na Constituição da República Federativa do Brasil.

O presente trabalho será desenvolvido por meio de pesquisa bibliográfica e documental acerca das diferentes vertentes inerentes ao sistema prisional brasileiro, trazendo dados retirados de leis, doutrinas, teses e dissertações que fundamentem as ideais postas no discorrer do estudo, e que auxiliem na resolução do problema proposto, consequentemente atingindo os objetivos.

Importante ressaltar que o foco deste trabalho consiste em realizar uma defesa da dignidade da pessoa humana diante dos princípios de um Estado Democrático de Direito. Ora, se o indivíduo praticou um delito e foi condenado a uma pena privativa de liberdade, a única coisa que deve ser podada dessa pessoa é, na medida do possível, estritamente a liberdade.

\section{METODOLOGIA}

\section{A dignidade da pessoa humana e a questão carcerária}

De acordo com Greco (2017), a sociedade se satisfaz apenas com o pagamento pelo mal cometido pelo infrator, desde que essa compensação seja em forma de privação de liberdade, caso seja uma pena restritiva de direitos ou multa, a sensação é de impunidade. Como ocorria no passado, ainda hoje a população

\footnotetext{
${ }^{1} \mathrm{O}$ Direito Penal do Inimigo, idealizado por Günther Jakobs, seria um direito penal despreocupado com direitos e garantias fundamentais, pois o infrator não deveria ser tratado como cidadão, mas como um inimigo do Estado. O Direito Penal do Inimigo se relaciona com a teoria da Racionalidade Penal moderna no que tange à duplicidade do direito penal, o Direito Penal do Inimigo propunha a divisão entre um direito penal para o cidadão e um direito penal para o inimigo, enquanto a Racionalidade Penal Moderna distingue um sistema de justiça paro jovens e outro para adultos.
} 
se regozija com o sofrimento do infrator. Em sua obra "As misérias do processo Penal", Carnelutti (2015) faz uma interessante distinção entre o delinquente e o encarcerado:

O delinquente, até que não seja encarcerado, é uma outra coisa. Confesso que o delinquente me repugna; em certos casos me causa horror. Para mim, entre outros, o delito, o grande delito, me aconteceu de vê-lo pelo menos uma vez, com os meus olhos. Os briguentos pareciam duas panteras; e permaneci estático, horrorizado; contudo bastou que visse um dos dois homens, que tinha posto por terra o outro com um golpe mortal, enquanto os policiais, providencialmente acudiam, metendo-lhe as algemas, para que do horror nascesse a compaixão. A verdade é que, apenas algemado, a fera se tornou homem.

O Estado Brasileiro é omisso às deficiências do sistema prisional, omissão essa que vem sendo debatida em diversos setores da sociedade, inclusive há discussões no Supremo Tribunal Federal, que no caso da ADPF 347, reconheceu um Estado de Coisas Inconstitucional no que tange as violações graves ocorridas nos presídios brasileiros e a inércia estatal na resolução do problema.

Dados mostram que a população carcerária brasileira é composta em sua grande maioria por pessoas negras, de baixa renda, com baixo nível de escolaridade e advindas de comunidades negligenciadas pelo estado. Aspecto que nos remete a um amplo debate acerca das possíveis explicações que possam esclarecer essa realidade.

É importante salientar a necessidade de respeitar os princípios fundamentais presentes no Estado Democrático de Direito, respaldado pela constituição federal que enraíza a Dignidade da Pessoa Humana no ordenamento jurídico pátrio. No âmbito internacional esse tema ganha visibilidade por meio de diversos importantes pactos em que o Brasil é signatário, entre eles o Pacto de San José da Costa Rica.

Castilho (2015) que, o reconhecimento e a proteção da dignidade da pessoa humana foram fruto de violações da integridade física e psicológica de grandes coletividades de seres humanos, o que acabou por desenvolver uma reação a essas atrocidades cometidas, resultando no surgimento de regras protetivas.

A negligência das autoridades brasileiras perante o sistema carcerário é escancarada, e por motivos políticos e sociais não há uma mobilização contrária, salvo por parte de algumas organizações e do poder judiciário, porém de forma ainda tímida. É urgente a necessidade de repensar o modelo carcerário, discutir sobre o real objetivo da pena; é ressocializar o preso, é servir de exemplo para terceiros, é vingança pela lesão social causada? A partir da óbvia resposta nos moldes das ciências criminais atual a resposta é lógica. Para isso as ações devem ir de encontro ao que se pretende.

A resposta, na verdade, encontra-se em um conjunto de ações. Não basta, tão somente tentar melhorar a vida dos presos dentro do sistema penitenciário. Temos que pensar em programas sociais, que antecedam a prática da infração penal, como também em programas destinados à ressocialização do preso que, certamente, após algum tempo, nos países que não adotam a pena de morte e a pena de prisão perpétua, voltará ao convívio em sociedade. (GRECO, 2016)

Atualmente muitos aspectos ligados ao sistema carcerário vêm sendo ventilados pela mídia, a exemplo de pessoas transexuais frequentarem presídios masculinos ou femininos, as constantes e violentas rebeliões, a soltura de presos durante a pandemia causada pelo coronavírus, entre outros, o que acaba provocando um debate social muitas vezes desprovido de conhecimento científico, mas que acaba produzindo efeitos no sistema prisional. 


\section{DISCUSSÃO TEÓRICA}

\section{Aspectos históricos do sistema carcerário}

É evidente que a liberdade é uma garantia muito cara ao ser humano, infelizmente por motivos diversos, entre esses, a própria característica da convivência social, esse direito pode ser podado de forma absoluta da vida de uma pessoa, sendo esse fato um dos mais dramáticos, porém necessário, a serem suportados por qualquer animal, com nós seres humanos não é diferente. A pena privativa de liberdade como conhecemos hoje já sofreu diversas mutações ao longo da história, um desenvolvimento talvez extremamente lento do ponto de vista prático. Para corroborar com o exposto anteriormente, Garutti et al. (2012) leciona que,

Não se pode desenvolver qualquer discussão a respeito do sistema carcerário, bem como a sua evolução histórica, sem antes discorrer sobre a origem da pena, uma vez que a existência do sistema penitenciário está ligada ao da pena imposta ao transgressor das normas sociais, constituídas juridicamente, tanto como castigo, quanto reparação do dano praticado à pessoa, pertencente à sociedade.

Em um primeiro momento as penas eram caracterizadas pela ausência do Estado, e era decorrente do próprio convívio social, já que é próprio do arbítrio humano o cometimento de falhas, seja de forma proposital ou acidental, o fato é que para cada ação existe uma reação, e nesta fase a retribuição por uma agressão praticada se dava pelo próprio ofendido ou por outro membro do grupo, sendo os bens mais importantes da sociedade protegidos pela autotutela, prevalecendo a lei do mais forte. Essa modalidade de pena é chamada de vingança privada, Greco (2016) ensina que "o único fundamento da vingança era a pura e simples retribuição a alguém pelo mal que havia praticado".

A denominada fase da vingança divina se confunde com a vingança privada no que tange ser a vítima a parte responsável por retribuir o mal causado, já a distinção, reside principalmente no que tange ao fundamento da pena, que nesta fase se dá para prestar contas com divindades. Garutti et al. (2012) diz que "acreditava-se que os deuses fossem guardiões da paz e eventuais crimes cometidos seriam considerados com/o afronta às divindades e a punição passa a existir para aplacar a ira divina e regenerar a alma do infrator".

Após passarmos pelas fases da vingança privada e da vingança divina, observou-se a necessidade de um julgamento mais isonômico, a vingança deixa de ficar ao bel prazer do ofendido ou terceiro pertencente ao grupo e passa a ser realizada pelo estado. A esse propósito faz-se mister trazer a inteligência de Greco (2016), lecionando que "o Estado chamou para si a responsabilidade de não somente resolver os conflitos, como também a de aplicar a pena correspondente ao mal praticado pelo agente". As penas continuam baseadas na lei de talião, que dá o tom da proporcionalidade, mas as mesmas continuam tendo um caráter extremamente cruel e sem observância dos princípios do direto penal tal quais conhecemos hoje. Garutti et al. (2012), descreve que:

O poder público passou a regulamentar as formas possíveis de castigo através do ente soberano que era aplicado de acordo com os seus interesses. Embora, ainda, conservasse a lei do Talião, todavia não mais aos critérios da vítima ofendida, apesar de a punição continuar violenta, desproporcional, atroz e desumana. A pena de morte, prática comum 
desde as primeiras civilizações, não se restringia apenas ao réu, mas atingia a todos de sua família. Não só a pena de morte como também açoitamentos, mutilações, os inúmeros suplícios físicos e os desterros.

As primeiras prisões modernas que surgiram foram as eclesiásticas, que por muito tempo funcionaram de forma concomitante as prisões do Estado. Importante salientar que apesar dos objetivos serem distintos, ambas tinham uma característica em comum que era a afronta à dignidade humana através de penas extremamente cruéis. Greco (2016), descreve a prisão eclesiástica como mais suave do que a prisão secular até então existente, pois buscava conduzir ao arrependimento do preso através da meditação e da oração. No entanto, no século XII surgiram cárceres subterrâneos caracterizados por não mais sair aqueles que ali adentrassem.

As penas de morte e cruéis gradativamente começam a perder espaço, prevalecendo as penas privativas de liberdade, então começa a surgir o denominado período humanitário, o modelo anterior passa a ser repensado a partir de obras de grandes nomes da época, entre os principais podemos citar Beccaria (2006), através da obra "dos delitos e das penas"; John Howard, que foi um obstinado pela melhoria do sistema penitenciário; Jeremy Benthan, criador do Utilitarismo do Direito.

Beccaria (2006) deixa muito clara sua insatisfação com o modelo de prisão vigente a sua época quando em sua obra "dos delitos e das penas" expressa seus ideais humanitários quando diz que:

À proporção que as penas forem mais suaves, quando as prisões deixarem de ser a horrível mansão do desespero e da fome, quando a piedade e a humanidade adentrarem as celas, quando finalmente, os executores implacáveis dos rigores da justiça abrirem o coração à compaixão, as leis poderão satisfazer-se com provas mais fracas para pedir a prisão.

Sobre a obra de Beccaria, leciona Greco (2016), que "suas ideias refletiam o sentimento de um povo cansado de ser oprimido pelos governantes inescrupulosos, cruéis e corruptos, desprovidos de legitimidade para administrar a res pública".

John Howard contribuiu muito para humanização das penas através de sua experiência prática, pois trabalhava diretamente com as prisões inglesas e fez viagens para conhecer a realidade de várias prisões no continente europeu. Greco (2016) traz as bases para cumprimento da pena defendidas por Howard em seu livro Estate of Prisions, que seriam a higiene e alimentação, disciplina distinta para presos provisórios e os condenados, educação moral e religiosa, trabalho, sistema celular mais brando. Muito importante no combate as barbáries cometidas nas prisões, os ideais de Jeremy Bentham foram de encontro aos ideais do direito natural, combatendo a existência de um contrato social.

Para Bentham, o cidadão deveria obedecer ao Estado, não pelo fato que estaria a ele vinculado por um suposto contrato social, mas sim porque a obediência contribuiria para a felicidade geral, ao contrário da desobediência, que a todos prejudicava. A felicidade geral, entendida como interesse da comunidade como um todo, era fruto de um cálculo de natureza hedonista, ou seja, o resultado da soma do bem comum e das dores dos indivíduos. (GRECO, 2016)

Diante da ascendência dos ideais dos pensadores iluministas, o objetivo da prisão passa ser repensado, dando início ao período científico, onde a pena passa a ser encarada como uma ciência. Segundo Garutti et al. (2012) "o criminoso, bem como as causas que o levaram a cometer o delito, passou a ser objeto de investigação. 
Esse período, que tem como referência a escola positiva, tem como grande ícone o médico italiano Cesare Lombroso, em que suas ideias, através do estudo morfológico do delinquente, serviram como marco para o início da cientificidade da pena, ainda que hoje seus ideais sejam ultrapassados. Segundo Balera et al. (2013):

Sua teoria teve por base a análise de centenas de casos e estabeleceu tendências comportamentais da grande maioria dos dementes e, por conseguinte, dos delinquentes: frequente realização de tatuagens (com diversos significados, muitas vezes com conteúdo obsceno); vaidade excessiva; preguiça, insensibilidade à dor; ausência de senso de moralidade; vícios na sexualidade; desvios e impulsos excessivos em sua conduta, entre outras características. Sempre negando o livre-arbítrio e, por conseguinte, reforçando o determinismo, a teoria de Lombroso pretendia interpretar o comportamento social a partir de características fisiológicas e biológicas.

O período da Nova Defesa Social surge a partir da fundação do Centro de Estudos da Defesa Social, que tinha por objetivo estudar o fenômeno criminal de forma ampla. Seu idealizador, Filippo Gramática, tinha por finalidade primordial a ressocialização do preso através de um sistema prisional que garanta ao preso todas as prerrogativas inerentes ao estado democrático de direito, principalmente no que tange à dignidade da pessoa humana. Garutti et al. (2012) leciona que os ideias desse período objetiva defender o sistema carcerário como um todo, pois o modelo atual não regenera, nem ressocializa o preso, muito pelo contrário, perverte, corrompe e destrói a saúde e a personalidade do encarcerado, além de onerar o Estado. Defendendo inclusive que o cárcere deve ser apenas para os delinquentes mais perigosos. Importante se faz o estudo desse contexto histórico para perceber o quanto o sistema carcerário brasileiro evoluiu, e em que patamar de desenvolvimento nos encontramos atualmente.

\section{A triste realidade do sistema prisional brasileiro e a decretação de estado de coisas inconstitucional pelo STF}

Diante das garantias constitucionais impostas ao Estado sobre o sistema carcerário, é importante trazermos dados fidedignos para nos possibilitar mensurar a realidade encontrada hoje no sistema carcerário brasileiro. Dados do infopen, de junho de 2019, nos trazem uma população carcerária de 752.277 presos no Brasil, o que nos chama a atenção é a expressividade de presos provisórios que são 248.929. Esse dado deixa claro a fragilidade do sistema judiciário brasileiro em se fazer justiça de forma célere, pois é amedrontador saber que praticamente $30 \%$ dos presos estão encarcerados sem o devido processo legal. O Estado brasileiro precisa urgentemente buscar soluções factíveis a curto prazo para resolução dessa disfunção legal tão maléfica ao Estado Democrático de Direito. Rangel et al. (2016) advoga no sentido que essa população carcerária tem um perfil seletivo, além das condições oferecidas pelo sistema prisional estarem longe da previsão legal. Irregularidade diversas são encontradas nos presídios, comparando as violações de direitos, inclusive, com as que ocorriam nos campos de concentração nazistas.

Importante destacar que o déficit de vagas no sistema prisional é gritante, sendo que temos aproximadamente 750.000 presos para cerca de 450.000 vagas nos presídios, resultando em um déficit de 300.000 vagas no sistema, causando uma superlotação que logicamente irá causar a violação de diversas garantias do preso, atingindo de forma quase que letal a dignidade da pessoa humana. Neste sentido leciona 
Sarlet (2019):

Nessa perspectiva, consagrando expressamente, no título dos princípios fundamentais, a dignidade da pessoa humana como um dos fundamentos do Estado Democrático de Direito (art. 1.o, III, da CF), a CF - a exemplo do que ocorreu pela primeira vez e de modo particularmente significativo na Lei Fundamental da Alemanha (1949) -, além de ter tomado uma decisão fundamental a respeito do sentido, da finalidade e da justificação do exercício do poder estatal e do próprio Estado, reconheceu categoricamente que é o Estado que existe em função da pessoa humana, e não o contrário, já que o ser humano constitui a finalidade precípua, e não meio da atividade estatal. Em outras palavras, no momento em que a dignidade é guindada à condição de princípio estruturante e fundamento do Estado Democrático de Direito, é o Estado que passa a servir como instrumento para a garantia e promoção da dignidade das pessoas individual e coletivamente consideradas.

Essa superlotação ocorre devido a diversos fatores entre elas podemos citar o excesso de leis penais, o excesso de prisões provisórias, o pouco uso de penas alternativas, a não ressocialização do preso, políticas públicas ineficientes, entre outros aspectos que são potencializadores de criminalidade.

O excesso de leis penais é uma característica do nosso poder legislativo que tenta a todo momento criar leis midiáticas, com o claro objetivo de autopromoção. A inobservância do princípio da intervenção mínima é um fator preponderante para a criminalização excessiva de condutas que violam bens que poderiam ser protegidos por outros ramos do direito. Essa demasiada produção de leis acaba por flexibilizar a aplicação do direito penal e por consequência enfraquecê-lo, dando a impressão que temos leis brandas e que alguns são inatingíveis.

Outro aspecto em que remanescem parcos questionamentos e dúvidas, é o fato de que a elaboração desordenada de leis remete à confusão e enfraquecimento do Direito Penal, mormente porque essa elaboração massificada dá notoriedade à intenção de atender a um Direito Penal que insiste em se impor através da força, ou seja, aquele robustecido pelas manchetes dos holofotes dos midiáticos noticiários. (PEDROSO et al., 2019)

O número de presos provisórios acaba por potencializar as injustiças, que normalmente são cometidas contra pessoas pertencentes a classes sociais menos favorecidas e que necessitam por exemplo da defensoria pública. A defensoria pública por sua vez tem uma estrutura muito aquém das suas obrigações perante a sociedade, contando ainda com a morosidade do poder judiciário, gerando assim uma disparidade entre as garantias do preso e a realidade do cárcere. Segundo Soares Junior et al. (2016):

A demografia apresentada reflete o perfil do preso brasileiro que se mantém há anos entre jovens, negros e de baixa escolaridade: $75 \%$ têm entre 18 a 34 anos de idade; $67 \%$ possuem ensino fundamental incompleto; $67 \%$ são compostos por negros, número maior que o apontado pelo Censo do IBGE de 2010, cuja população autodeclarada negra representava $51 \%$ da população brasileira.

O código penal, em seu artigo 59, leciona que as penas devem ser suficientes e necessárias para a reprovação e prevenção do crime. Hoje nos deparamos com diversas penas desproporcionais, prisões sem justificativas plausíveis que nos remetem ao período em que as penas servem apenas como retribuição ao mal causado a outrem ou a sociedade, o caráter ressocializador da pena fica em segundo plano, sendo importante destacar que quanto mais se prende, menos se ressocializa e mais potencializa a violência.

Não seria desarrazoado inclinar-se ao ideal de que deve ter a pena a função de zelar pela convivência pacífica dos homens organizados em sociedade, prescindindo-lhe o selo conotativo de castigo, retribuição do mal cometido, intimidação ou de segregação do indivíduo da sociedade, pois que é dever do "remédio social" prescrever ao homem que transgride a norma penal estabelecida, não o simples castigo, mas a recuperação, a 
reeducação para que não reitere a realização de delitos. Entendendo ser necessário nortear a vida dos homens para a realização constante do bem, não se pode, então, praticar o mal. Mas que mal seria esse? Não é outro, senão, o desprezo daquele que opta pelo mal. (PEDROSO et al., 2019)

Muitos dos aspectos que aqui foram discutidos são frutos de um fator macro que contribui diretamente para o fracasso do sistema prisional brasileiro, que é a ineficiência de políticas públicas perante a problemática apresentada, o problema de gestão vai muito além da falta de competência técnica, é uma questão de vontade política para transformar a realidade. Cabe salientar que a política pública de segurança pública não se restringe em investimentos em estrutura de presídios, em estrutura policial e sistema judiciário. A problemática é uma 'teia' que perpassa por uma educação de qualidade, trabalho e renda, lazer, saúde, entre outros parâmetros necessários à nossa qualidade de vida. Para corroborar o exposto anteriormente Rangel et al. (2017) nos ensina que a redução de investimentos em áreas como assistência social, saúde, educação e moradia, promove um efeito direto no incremento de funções penais e policiais sobre aquelas populações que deixaram de ser assistidas pelo poder público.

Fica evidente que o enfrentamento ao problema destacado vai além das fronteiras de um único ministério, a exemplo o da segurança pública, ou de um único poder, a exemplo do poder executivo, devendo-se estimular um trabalho intersetorial que envolva diversos atores sociais e que se desenvolva uma real harmonia entre os poderes para um combate profícuo a toda forma de ofensa aos direitos fundamentais previsto na nossa constituição.

Diante desse cenário de violação dos direitos fundamentais das pessoas privadas de liberdade - mesmo com a existência de experiências exitosas no campo das assistências em poucas unidades prisionais, mas sem nenhum tipo de direcionamento ou ordenamento hobbesiano do caos social - foram pensadas ações intersetoriais para a política penal, como, por exemplo, as políticas de saúde, de educação e do trabalho, instituídas nas respectivas pastas de responsabilidade do executivo federal, estaduais e municipais, de forma interfederativa e colaborativa. (SOARES JUNIOR et al., 2016)

Fica claro que a questão não é investir recursos financeiros, pois no Brasil temos um alto gasto com o sistema prisional, o aspecto que deve ser repensado é sobre a qualidade nos investimentos, uma maior especialização de gestão voltada ao sistema carcerário. Leciona Machado et al. (2015) que:

Embora o ideal reintegrador configure o modelo legal de execução penal contemplado na LEP, o objetivo declarado mostra-se de difícil implantação. As práticas dos atores envolvidos na divisão do trabalho penitenciário sugerem a concorrência de outras racionalidades punitivas, especialmente a retribuição e a prevenção geral negativa. As dificuldades em se atender às exigências técnicas do Governo Federal para a liberação de recursos e a falta de capacitação técnica das burocracias estaduais agravam a operacionalização das políticas idealizadas pelos gestores. O distanciamento entre o modelo idealizado pela LEP e a realidade do sistema penitenciário brasileiro evidenciam que a previsão legal não alterou a precariedade das políticas penitenciárias voltadas à capacitação profissional no regime fechado.

A lógica para aperfeiçoar o sistema carcerário reside justamente em se colocar no lugar do preso, dentro e fora do presídio, e indagar sobre quais fatores socioculturais o levaram a delinquir e quais motivos levam à reincidência, é necessário um sistema de controle e prevenção de crimes que perpassem a fronteira unicamente da segurança pública e do poder judiciário, deve-se combater o crime na raiz do problema, para que o indivíduo não tenha a necessidade de cometer infrações penais. 


\section{Análise da ADPF 347}

As violações massivas de direitos humanos ocasionadas pela patologia impregnada no sistema prisional brasileiro, levou o STF durante o julgamento da ADPF 347 a reconhecer o Estado de Coisas Inconstitucional, outro momento similar em que foi adotada a tese foi no Recurso Extraordinário 580.252, onde se discutiu a responsabilidade civil do Estado perante a superlotação dos presídios. Conforme leciona Castilho (2018), o Estado de Coisa Inconstitucional originou-se da violação maciça de direitos fundamentais de um número significativo de pessoas, seguidos pela falta de vontade política ou da desarticulação institucional que visem resolver os problemas evidenciados.

Para caracterização do Estado de Coisas inconstitucionais faz-se mister a observância dos critérios elencados acima, que devem ser analisados de forma cuidadosa para que seja possível sua aplicação, afim de se evitar um ativismo judicial exacerbado, vale lembrar que o STF é o guardião da constituição, dessa forma é viável a adoção de instrumentos eficazes para combater as omissões inerentes aos direitos protegidos pela nossa carta maior. De acordo com Campos (2016):

A declaração do $\mathrm{ECl}$ e os remédios estruturais, que seguem à decisão dessa natureza, revelam ativismo judicial de dimensão predominantemente estrutural. Isso não significa, todavia, que seja aprioristicamente ilegítimo. Sem embargo, apenas o ativismo judicial antidialógico pode ser considerado ilegítimo a priori. Com isso, a ideia de diálogos institucionais é uma boa resposta às objeções de ordem democrática e institucional contra a expansão de poder por juízes e cortes. O ativismo judicial estrutural, presente na declaração do $\mathrm{ECl}$, pode ser considerado legítimo se, além de observarem-se os seus pressupostos, permitir ou catalisar o diálogo entre os poderes e destes com a sociedade.

O Estado de Coisas Inconstitucional (ECI) surgiu na corte suprema colombiana e se fundamenta com base na omissão estatal referente a ineficácia legislativa ou ineficiência executiva quanto a garantia de direitos fundamentais. Nesse sentido leciona Azevedo (2016):

O descumprimento do dever de legislar ou de expedir normas regulamentadoras decorreria da inércia dos poderes políticos, máxime o legislador, em criar as condições necessárias para o gozo efetivo dos direitos fundamentais, ou em deixar de afastar ou minimizar os obstáculos reais, as limitações fáticas que impeçam a fruição desses direitos, e isso independentemente da tipologia ou especificidade dos enunciados constitucionais.

Uma inconstitucionalidade pode ocorrer por ação ou por omissão, a decisão proferida pela suprema corte brasileira, assim como ocorreu na Colômbia, se justifica por uma inconstitucionalidade por omissão, já que é inerente à inércia do poder estatal em observar e garantir os diretos fundamentais dos presos através de políticas públicas voltadas ao respeito à dignidade da pessoa humana, que no caso em tela não é apenas do preso, mas da sociedade em geral, pois a omissão estatal no que se refere ao sistema carcerário promove o aumento da violência devido a não ressocialização do preso, que na maioria das vezes volta a cometer o mesmo delito, quando não mais graves. Corroborando com o exposto acima, Magalhães (2019) diz que "a ausência de medidas legislativas, administrativas e orçamentárias eficazes representa falha estrutural a gerar tanto a violação sistemática dos direitos quanto a perpetuação e o agravamento da situação".

Os efeitos práticos da decisão ainda são tímidos, porém o Supremo Tribunal Federal, na decisão, determinou a liberação de verbas do Fundo Penitenciário Nacional e reforçou a obrigatoriedade da realização das audiências de custódia no prazo máximo de vinte e quatro horas. No que se refere a liberação do fundo 
penitenciário, como já debatido no presente trabalho, esse investimento deve ser acompanhado de gestão técnica e competente, para dessa forma obter resultados positivos. As audiências de custódia visam diminuir o encarceramento em massa, principalmente no que se refere a presos provisório, pois a autoridade competente irá avaliar de prontidão a legalidade da prisão e a possibilidade de relaxamento de forma imediata. Taquary (2019), diz a adoção da tese no Brasil acarretou na aplicação da audiência de custódia para presos em flagrante delito, momento em que o juiz aprecia o pedido para converter em prisão preventiva ou determinar a soltura do preso, com a possibilidade de aplicação de medidas cautelares. Sobre o desbloqueio do Fundo penitenciário Nacional, Magalhães (2019), traz uma interessante informação acerca dessa medida:

No curso do julgado, o então advogado-geral da União, Luís Inácio Lucena Adams, informou aos ministros que tais recursos não estavam mais contingenciados. Por essa razão, o Ministro Zavascki reconheceu que o problema não seria, tanto, a falta de recursos, mas a inexistência de um plano de ação para alocá-los. O Ministro Barroso, a seu turno, questionou a utilidade da medida cautelar em face da notícia do advogado-geral da União, o que o levou a estabelecer um prazo de 60 dias para a demonstração das informações trazidas.

O Estado de Coisas Inconstitucional, apesar de frequentes divergências, é um instrumento interessante para evitar violações de direitos, já que sabemos que o sistema jurídico brasileiro é extremamente volúvel e seletivo, mudando de posição de acordo com o réu. Um claro exemplo foi o caso de Adriana Ancelmo, mulher do ex-governador do Rio de Janeiro Sérgio Cabral. A ex-primeira-dama que estava em regime fechado foi contemplada pela garantia contida no art. 318 do Código de Processo Penal, que leciona que a mulher grávida ou que for mãe ou responsável por crianças ou pessoas deficientes terá sua prisão preventiva substituída por domiciliar. A decisão foi perfeita, no entanto o que se questionou foi que a mesma garantia não se estendia a maioria das presas do país, deixando evidente a seletividade do caso. Durante seu voto no Habeas Corpus 143.641, o ministro Ricardo Lewandowski descreveu que:

Por essas razões, somadas ao reconhecimento, pela Corte, na ADPF 347 MC/DF, de que nosso sistema prisional encontra-se em um estado de coisas inconstitucional, e ainda diante da existência de inúmeros julgados de todas as instâncias judiciais nas quais foram dadas interpretações dissonantes sobre o alcance da redação do art. 318, IV e V, do Código de Processo Penal (v.g., veja-se, no Superior Tribunal de Justiça: HC 414674, HC 39444, HC 403301, HC 381022), não há como deixar de reconhecer, segundo penso, a competência do Supremo Tribunal Federal para o julgamento deste writ, sobretudo tendo em conta a relevância constitucional da matéria. (BRASIL, 2018)

No julgamento do citado Habeas Corpus, o Supremo Tribunal Federal, julgou no sentido de determinar a substituição da prisão preventiva por prisão domiciliar de todas as presas que comprovassem os requisitos do art. 318 do Código de Processo Penal. Essa justa decisão garantiu que a quebra da isonomia que ficou caracterizado no caso Adriana Ancelmo não fosse perpetuada e gerando mais ainda a sensação de injustiça e seletividade do direito penal, e mais do que isso, trouxe alento ao princípio da dignidade da pessoa humana.

Uma consequência grave das violações que foram aqui relatadas são as violentas rebeliões que ocorrem nos presídios brasileiros, a exemplo do Carandiru (1992), Urso Branco (2002), Casa de Custódia de Benfica (2004), Compaj em Manaus (2017), Alcaçuz no Rio Grande do Norte (2017), Altamira no Pará (2019), entre muitas outras que deixaram o país perplexo e mostraram de forma transparente a falência do sistema 
prisional brasileiro, tendo muitas dessas rebeliões sido denunciadas a Corte Internacional de Direitos Humanos, gerando uma imagem extremamente negativa do Brasil a nível mundial. Greco (2016) diz que "as rebeliões nas penitenciárias brasileiras têm sua razão de ser. Existem presídios superlotados, muitos deles com três, quatro ou mesmo cinco vezes a sua capacidade".

\section{Garantias fundamentais inerentes ao preso}

Diversos dispositivos da Constituição da República Federativa do Brasil e da Lei de Execução Penal trazem o rol de garantias inerentes ao cidadão preso, direitos esses que são também protegidos por diversas convenções internacionais em que o Brasil é signatário, devendo, portanto, observar e proteger esses direitos à luz da dignidade da pessoa humana.

Em seu art. 5ㅇ a Constituição federal dispõe que ninguém será submetido a tortura nem a tratamento desumano ou degradante. A garantia prevista no citado dispositivo é inerente a todo ser humano, não criando a carta maior do nosso país qualquer tipo de exceção, devendo logicamente esta garantia ser respeitada no âmbito do sistema prisional

Nosso sistema constitucional veda a pena de morte, exceto em caso de guerra declarada, além de não permitir penas de caráter perpétuo, de trabalhos forçados, de banimento e penas cruéis. 0 art. 5으, inciso XLVII da Constituição Federal configura uma limitação da pena em respeito ao princípio norteador do nosso sistema jurídico, a dignidade da pessoa humana. Dimoulis (2016), advoga que as vedações impostas no art. 5ㅇ, inciso XLVII, alínea c, são utilizadas para declarar inconstitucionais penas tidas como cruéis, degradantes e desumanas, e como a ordem é de caráter genérico, pode ser atacada qualquer pena considerada moralmente inaceitável em um Estado de direito por ofender a dignidade humana.

Uma importante garantia é a de cumprimento de pena em estabelecimentos distintos, de acordo com a natureza do delito, a idade e o sexo do apenado (art. 5ㅇ, XLVIII da CF). O artigo em questão é de suma importância para garantia de um sistema prisional ressocializador e humano, já que sabemos que existem individualidades do preso que devem ser observadas sob a consequência, por exemplo, de fortalecimento de facções criminosas, torturas, estupros, entre outras mazelas conhecidas na realidade dos presídios brasileiros. Recentemente o Ministro Luís Roberto Barroso, do Supremo Tribunal Federal, autorizou a transferência de presas transexuais para presídios femininos. Interessante reflexão sobre o tema é feita por Mello (2018) dispondo que:

Desse modo, dada a sua relevância e considerando a existência de relativamente poucas decisões do STF que envolvem diretamente a sua proteção e promoção (como direito fundamental autônomo) do direito da população LGBTT, a decisão se tornou um importante marco para o tratamento jurídico do tema. Especialmente porque extrapola o conteúdo meramente processual penal e estabelece conexões com direito civil, por exemplo, ao tratar do direito ao registro civil de acordo com a sua identidade de gênero e princípios fundamentais, mas também em virtude da atualidade de algumas discussões relevantes que dizem respeito a uma vida livre de violência, de discriminação e com respeito à dignidade da pessoa humana, como bens jurídico-constitucionais.

O art. 5으, inciso XLIX, da constituição Federal assegura o respeito à integridade física e moral do preso. Provavelmente uma das garantias mais desrespeitadas pelo sistema prisional brasileiro, já que visivelmente 
vemos violações principalmente causadas pela superlotação dos presídios, atualmente não temos uma política penal apta a garantir esses direitos. Como leciona Taquary et al. (2019):

O Ordenamento Jurídico Brasileiro tem como fundamento o princípio da Dignidade da Pessoa Humana, que permeia todas as relações humanas e as estabelecidas pelo Estado enquanto Administração Pública, motivando sua observância na Administração Penitenciária, em especial na execução da pena.

Um tema atual relevante a ser destacado é sobre os efeitos da pandemia causada pelo coronavírus no sistema prisional, já que existe uma preocupação muito grande no que diz respeito a estrutura dos presídios e a superlotação, causando um risco incalculável à saúde dos usuários do sistema. Várias entidades, a exemplo da $\mathrm{OAB}$ e do $\mathrm{CNJ}^{2}$, já se manifestaram favorável à desinternação de adolescentes que cumprem medidas socioeducativas. Em São Paulo a justiça determinou a soltura de mil e duzentos presos, que pertencem ao grupo de risco, para conter a pandemia.

Essas medias obedecem além dos dispositivos legais presentes na constituição federal, à lei de execução penal, que também tem dispositivos que são de suma importância para garantia da dignidade dos presos, principalmente no que tange a assistência que o Estado deve proporcionar ao preso. A lei 7.210 de 1984, em seus artigos $10^{3}$ e $11^{4}$ (BRASIL, 1984).

\section{Direitos e garantias violados pelo sistema prisional brasileiro}

Já foi debatido no presente estudo sobre as garantias inerentes ao preso, neste tópico faz necessário deixar transparente como o sistema prisional fere de forma grave os direitos fundamentais, principalmente trazendo as violações à dignidade da pessoa humana, que é o princípio basilar de um verdadeiro Estado Democrático de Direito, pois este surgiu justamente para combater os abusos do próprio Estado contra o cidadão. De acordo com Malheiro (2016):

É um dever social a aplicação concreta do princípio constitucional da dignidade da pessoa humana porque ele é o núcleo axiológico do direito contemporâneo nacional, o núcleo exegético do ordenamento jurídico brasileiro, o núcleo essencial de irradiação dos direitos humanos e o fundamento da República Federativa do Brasil.

Ao adentrarem no sistema prisional brasileiro, talvez o primeiro direito a ser violado seja a integridade física e moral, já que devido as condições de superlotação do presídio, a não realização, muitas vezes, da separação de presos, acabam por gerar violência, inclusive sexual, entre os próprios presos, que se manifesta através de agressões físicas e psicológicas, há relatos inclusive de agressões promovidas pelos próprios agentes estatais, que deveriam assegurar os direitos do preso. Como se não fosse suficiente, as condições insalubres dos presídios acabam por atingir a saúde do indivíduo, deixando-os mais propensos a

\footnotetext{
${ }^{2} \mathrm{O}$ Conselho Nacional de Justiça editou medidas para atender as necessidades que o atual momento exige, devendo essas serem replicadas em todo o país. Foram estabelecidos procedimentos a serem realizados em todas as unidades prisionais e socioeducativas, visando a prevenção e propagação do novo coronavírus. As medidas objetivam a proteção de magistrados, agentes públicos e pessoas privadas de liberdade. Entre elas podemos citar: prevenção na realização de audiências judiciais nos fóruns; suspensão excepcional de audiências de custódia; ação conjunta com os Executivos locais na elaboração de planos de contingência; e suporte aos planos de contingência deliberados pelas administrações penitenciárias dos estados em relação a visitas.

${ }^{3}$ Art. 10. A assistência ao preso e ao internado é dever do Estado, objetivando prevenir o crime e orientar o retorno à convivência em sociedade. Parágrafo único. A assistência estende-se ao egresso.

${ }^{4}$ Art. 11. A assistência será: I - material; II - à saúde; III -jurídica; IV - educacional; V - social; VI - religiosa.
} 
aquisição de doenças graves. Segundo Lima et al. (2014):

O Estado, mesmo ciente de todas as condições subumanas a que os presos são expostos, continua negligenciando a situação do preso, tratando as prisões como um depósito de lixo humano e de seres inservíveis para o convívio em sociedade. Isso não apenas agrava a situação carcerária, como também demonstra o descaso das autoridades, com a violação do princípio garantido constitucionalmente: os Direitos e Garantias Fundamentais.

Uma questão importante a ser detalhada é acerca do direito fundamental à educação, é sabido que a maioria dos presos não tem acesso a programas educacionais formais nem informais. Esse fator gera uma preocupação principalmente quando pensamos em ressocialização, seria bem mais fácil a pessoa não reincidir se saísse do sistema prisional com uma formação, um emprego, uma renda, possibilitando-o seu sustento e o da própria família. Dados mostram que a maioria dos presos tem baixo nível de escolaridade, e se assim saem do sistema, a lógica é que os fatores que o levaram a delinquir irão persistir, a pena, sozinha, não irá ser apta a reinserção do preso na sociedade. Ribeiro et al. (2015), lecionam que poucos estabelecimentos oferecem educação formal, e os que ofertam essas atividades educativas, o fazem de forma ineficiente, não atendendo a demanda, principalmente devido à falta de estrutura. A ressocialização ocorreria de forma mais efetiva se o processo educacional fosse realizado com vínculos sociais e não meramente técnicos.

De todos os direitos fundamentais violados no âmbito carcerário brasileiro, a dignidade da pessoa humana é a mais atingida, pois esta é atacada toda vez que se nega o acesso aos demais direitos, é como se todos outros estivessem contidos nela. Para exemplificar, podemos citar o caso das mulheres detentas e da comunidade LGBT, que muitas vezes não têm acesso a um estabelecimento prisional adequado à suas individualidades, o que acaba ocasionando diversas lesões a dignidade da pessoa humana dessas pessoas. Para corroborar o exposto Araujo Neto (2017), ressalta que o problema do encarceramento de mulheres reside na ausência de estabelecimento próprio e adequado, pois falta berçário, locais destinados à gestante, à parturiente, e creches para abrigar as crianças. Sendo semelhante ao que ocorre com as minorias sexuais, que pelo encarceramento inadequado, acabam por sofrer violências sexuais e contraindo doenças sexualmente transmissíveis.

A dignidade da pessoa humana não pode ser dividida em classes, como se houvesse diferentes classes de humanos, uma superior que teria seus direitos mais fundamentais preservados; e outra inferior, que não teria direito sequer a dignidade. Obvio que um Estado Democrático de Direito não pode permitir tamanho absurdo, desta forma a dignidade humana é suprema a qualquer outro viés que possa colocar em risco a própria existência do Estado como garantidor dos direitos mais fundamentais dos seus cidadãos.

\section{CONCLUSÕES}

O sistema carcerário brasileiro precisa urgentemente de uma intervenção mais humana e preocupada com a garantia de direitos fundamentais, o que se percebe é uma omissão quase que completa por parte dos poderes estatais, isso quando os mesmos não contribuem para o agravamento do sistema por meio de ação, a exemplo do poder legislativo que para atender demandas midiáticas, abarrotam a legislação com dispositivos penais que poderiam ser substituídos por tutelas específicas de outros ramos do direito. 
Os poderes do estado precisam se unir em torno de um debate dialógico que permita uma intervenção eficiente para combater as violações de direitos no âmbito dos presídios brasileiros, e mais do que pensar intramuros faz-se mister analisar a problemática fora dos presídios, gerindo de forma inteligente políticas públicas voltadas a garantia das necessidades mais básicas da população, não é por acaso que o sistema prisional é praticamente composto por pessoas de classes sociais mais carentes, dotadas de um baixo nível de escolaridade e pertencentes a comunidades periféricas, é justamente na falta do agir estatal que nasce a criminalidade, na maioria das vezes por puro instinto de sobrevivência.

É de suma importância resolver a curto prazo o problema da superlotação dos presídios, já que a situação só se agrava, pois os dados mostram que as prisões no Brasil estão em uma crescente, não menos importante é observar as individualidades dos presos, não é correto encarcerar uma mulher em uma estrutura que não ofereça a mesma as condições necessárias para que a mesma possa ter suas necessidades básicas específicas atendidas, principalmente no que tange a mulher grávida e as que tenham filhos que dependam dos seus cuidados. Outra especificidade importante é a relacionada às minorias sexuais, comumente negligenciadas, o que acaba por provocar graves violações a sua saúde, integridade física e moral, a sua dignidade.

O problema do sistema prisional não é apenas do preso e suas famílias, é um problema social que atinge a todos os cidadãos, quando se fere direitos fundamentais de uma pessoa, essa ação não é de efeito estritamente local, mas atinge toda a sociedade de forma letal, pois a dignidade da pessoa humana vai além das fronteiras de uma pessoa ou de um local, fazendo uma analogia ao meio ambiente, uma pequena ação que o viole o atinge em sua totalidade. A sociedade brasileira precisa mudar a mentalidade, se despir de preconceitos e se questionar se o que estamos fazendo faz desse mundo um lugar melhor ou pior.

\section{REFERÊNCIAS}

ARAUJO NETO, O. I.. Uma análise sobre o Estado de Coisas Inconstitucionais do Sistema Carcerário Brasileiro e a Privatização de Presídios como solução. In: ENCONTRO NACIONAL DO CONPEDI, 16. Anais. Brasília: CONPEDI, 2017.

BALERA, J. E. R.; DINIZ, N. M.. A eticidade de pesquisas bioantropológicas de delinquência no cenário científico contemporâneo. Revista Bioética, Brasília, v.21, n.3, p.536545, 2013

BECCARIA, C.. Dos delitos e das penas. São Paulo: Martin Claret, 2006.

BRASIL. Constituição da República Federativa do Brasil. Brasília: DOU, 1988.

BRASIL. Lei de Execução Penal n. 7.210/84 de 11 de julho de 1984. Brasília: DOU, 1984.

BRASIL. Supremo Tribunal Federal. Todas as mulheres submetidas à prisão cautelar no sistema penitenciário nacional, que ostentem a condição de gestantes, de puérperas ou de mães com crianças com até 12 anos de idade sob sua responsabilidade, e das próprias crianças. Habeas Corpus n 143.641-SP. Relator: Ministro Ricardo
Lewandowski. DJ, 20 fev. 2018. Brasília: DOU, 2018.

CAMPOS, C. A. A.. Estado de Coisas Inconstitucional. Salvador: JusPodivm, 2016

CARNelutTI, F.. As Misérias do Processo Penal. 3 ed. São Paulo: Edijur, 2015.

CASTILHO, R.. Direitos Humanos. 3 ed. São Paulo: Saraiva, 2015.

CASTILHO, R.. Direitos Humanos. 5 ed. São Paulo: Saraiva, 2018.

DIMOULIS, D.. Direito Penal Constitucional: garantismo na perspectiva do pragmatismo jurídico-político. Belo Horizonte: Arraes, 2016

GARUTTI, S.; OLIVEIRA, R. C. S.. A Prisão e o Sistema Penitenciário: uma visão histórica. In: SEMINÁRIO DE PESQUISA DO PPE. Anais. Maringá: UEM, 2012.

GRECO, R.. Direito Penal do Equilíbrio: Uma Visão Minimalista do Direito Penal. 10 ed. Rio de Janeiro: Impetus, 2017. 
GRECO, R.. Sistema Prisional: Colapso Atual e Soluções Alternativas. 3 ed. Rio de Janeiro: Impetus, 2016.

LIMA, B. C.; LIMA, M. C.. A realidade do sistema prisional brasileiro: limitação dos direitos fundamentais nos presídios brasileiros. Iniciação Científica CESUMAR, v.16, n.1, p.67-77, 2014.

MACHADO, B. A.; SLONIAK, M. A.. Disciplina ou ressocialização? Racionalidades punitivas, trabalho prisional e política penitenciária. Rev. Direito GV, São Paulo, v.11, n.1, p.189-222, 2015.

MAGALHÃES, B. B.. O Estado de Coisas Inconstitucional na ADPF 347 e a sedução do Direito: o impacto da medida cautelar e a resposta dos poderes políticos. Rev. Direito GV, São Paulo, v.15, n.2, e1916, 2019.

MALHEIRO, E.. Curso de Direitos Humanos. 3 ed. São Paulo: Atlas, 2016.

MELLO, A. R.. O Supremo Tribunal Federal e o direito das travestis à unidade prisional feminina: comentários à decisão proferida no habeas corpus n. 152.491. Revista Direito em Movimento, Rio de Janeiro, v.16, n.1, p.193-211, 2018.

PEDROSO, V. A. M.; JARDIM, C. J. O.. O Castigo Abstrato e o Castigo Concreto: eficácia da estrutura da crueldade institucional pela ausência do direito. Sequência,

Florianópolis, n.81, p.202-225, 2019.

RANGEL, F. M.; BICALHO, P. P. G.. O alongamento do tempo de prisão e a violação de direitos na custódia de presos no Brasil. Avances en Psicología Latinoamericana, Bogotá, v.35, n.3, p.473-483, 2017.

RANGEL, F. M.; BICALHO, P. P. G.. Superlotação das prisões brasileiras: Operador político da racionalidade contemporânea. Estudos de Psicologia, Natal, v.21, n.4, p.415-423, 2016.

RIBEIRO, R. C.; OLIVEIRA, C. G.. As mazelas do sistema prisional brasileiro the sufferings of the brazilian prison system. Revista Jurídica, Anápolis, v.1, n.24, p.113-128, 2015.

SARLET, I. W.. Curso de Direito Constitucional. 8 ed. São Paulo: Saraiva Educação, 2019.

SOARES FILHO, M. M.; BUENO, P.. Michele Martins Gomes. Demografia, vulnerabilidades e direito à saúde da população prisional brasileira. Ciênc. Saúde Coletiva, Rio de Janeiro, v.21, n.7, p.1999-2010, 2016.

TAQUARY, E. O. B.; LEÃO, W. S. C.. O dialógo entre colômbia e brasil sobre o 'estado de coisas inconstitucional'. Revista de la Secretaría del Tribunal Permanente de Revisión, Assunção, v.7, n.13, p.193-212, 2019.

A CBPC - Companhia Brasileira de Produção Científica (CNPJ: 11.221.422/0001-03) detém os direitos materiais desta publicação. Os direitos referem-se à publicação do trabalho em qualquer parte do mundo, incluindo os direitos às renovações, expansões e disseminações da contribuição, bem como outros direitos subsidiários. Todos os trabalhos publicados eletronicamente poderão posteriormente ser publicados em coletâneas impressas sob coordenação da Cognitionis Publishing, da Companhia Brasileira de Produção Científica e seus parceiros autorizados. Os (as) autores (as) preservam os direitos autorais, mas não têm permissão para a publicação da contribuição em outro meio, impresso ou digital, em português ou em tradução. 